A) Check for updates

Cite this: Food Funct., 2018, 9, 179

\section{Consumption of plant food supplements in the Netherlands}

\author{
Suzanne M. F. Jeurissen, (DD * Elly J. M. Buurma-Rethans, Marja H. Beukers, \\ Martine Jansen-van der Vliet, Caroline T. M. van Rossum and R. Corinne Sprong
}

Received 5th August 2016, Accepted 6th November 2017 DOI: $10.1039 / \mathrm{c} 6 f \circ 01174 \mathrm{~h}$ rsc.li/food-function

\begin{abstract}
The use of food supplements containing herbs or other botanical ingredients (plant food supplements, PFS) is on the rise. In some cases, PFS can contain compounds that are toxic and may pose a health risk. To assess the potential health risks, information on the consumption of PFS is required, however, this was lacking for the Netherlands. In the current study, the consumption of PFS was investigated for several subgroups in the Dutch population, including children. Data from the Dutch National Food Consumption Surveys were used to get a first impression on the consumption of PFS. To obtain more detailed information, a specific PFS consumption survey was performed using online questionnaires. First, a screening survey was performed among a representative sample of 75100 adults and children of the Dutch population, followed by a main survey among 739 selected PFS users in eight different age and gender subgroups. The prevalence of PFS users in the Dutch population was approximately $10 \%$ for men, $17 \%$ for women and $13 \%$ for children. A wide variety of PFS was used, with around 600 different PFS reported, containing 345 different botanicals. The most frequently used botanicals were echinacea (Echinacea purpurea), ginkgo (Ginkgo biloba), cranberry (Vaccinium macrocarpon), ginseng (Panax ginseng) and algae (such as species belonging to the genus Spirulina or Chlorella). Because PFS are widely used in the Dutch population, it is important to evaluate the potential risks associated with PFS consumption in the Netherlands, including potential herb-drug interactions. The data collected in this study are of great value to assess these risks.
\end{abstract}

\section{Introduction}

The use of food supplements containing herbs or other botanical ingredients (plant food supplements, PFS) is on the rise. ${ }^{1}$ PFS have a 'natural' image and are often used because of their (supposed) health benefits. Food supplements are marketed in dose forms resembling medicinal products. According to the General Food Law (Regulation (EC) No. 178/2002 ${ }^{2}$ ), any food, including PFS, placed on the market has to be safe. However, in contrast to medicinal products, no pre-market safety assessment and authorization is needed when PFS, as well as other food supplements, are brought on the market in Europe. ${ }^{3}$ The legislation on botanicals in food supplements is not harmonized in Europe, and therefore PFS are subject to national legislation in EU Member States. Major differences exist among the rules for PFS. Several countries have lists with botanicals that are allowed (positive list) and/or prohibited (negative lists) for use in PFS and some have specific requirements

National Institute for Public Health and the Environment (RIVM), P.O. Box 1, 3720 BA Bilthoven, The Netherlands.E-mail: suzanne.jeurissen@rivm.nl; Tel: +31302744353 with respect to maximum levels and labelling. ${ }^{4}$ The BELFRIT project was an initiative to harmonize these lists of botanicals in Europe, starting with the lists of Belgium, France and Italy. ${ }^{5,6}$ In the Netherlands, the Herbal Preparations Decree in the Dutch Commodities Act contains a list of botanicals and botanical ingredients that are not allowed in PFS and other herbal preparations. In addition, the Herbal Preparations Decree prohibits to place on the market any herbal preparation that contains herbal substances in amounts that are detrimental to health. ${ }^{7}$ In most EU member states, a notification procedure has to be completed before a PFS can be placed on the market. The requirements for notification vary from submission of the product label only to submission of a safety dossier. $^{8}$ In the Netherlands, as well as in a few other EU member states, no notification system is set up for food supplements, including PFS, and as a consequence, there is no complete overview of PFS on the Dutch market.

In spite of the common perception among consumers that 'natural equals safe', some PFS may contain constituents that are toxic or even genotoxic and/or carcinogenic, and can cause (serious) adverse health effects (e.g. ref. 9-11). To assess the potential health risks posed by PFS, information on the consumption of PFS is required. Recently, the results of the 
PlantLIBRA consumer survey, conducted among adult PFS users in six European countries (Finland, Germany, Italy, Romania, Spain and the United Kingdom) were published. ${ }^{12}$ Overall, $18.8 \%$ of the screened respondents had used at least one PFS in the preceding year (range 9.6-22.7\% in the different countries). Across countries, 491 different botanicals were identified in the PFS consumed, with Ginkgo biloba (ginkgo), Oenothera biennis (evening primrose) and Cynara scolymus (artichoke) being most frequently reported. In this study, clear differences among countries in terms of botanicals used by consumers as PFS were observed. This may be due to the fact that current legislation is not harmonized at a European level, with differences between botanicals permitted in PFS among countries, as described above. In addition, some products may be on the market as (traditional) herbal medicinal products in some countries and as PFS in other countries. ${ }^{12}$ Also cultural differences may play a role.

Currently, detailed information on the consumption of PFS in the Netherlands is lacking. The aim of the current study was to investigate the consumption of PFS in various age and gender subgroups of the population, including children, in the Netherlands. Consumption data collected in the Dutch National Food Consumption Surveys were analysed to get a first impression on the percentage of PFS users in the Dutch population and to estimate the sample size needed for a specific PFS consumption survey. Thereafter, a specific PFS consumption survey was conducted among 75100 adults and children in the Netherlands to obtain detailed information on the consumption of PFS in the Netherlands. The results can be used to assess the potential health risks posed by PFS and to improve the monitoring of PFS consumption in the future.

\section{Materials and methods}

\section{Definition of plant food supplements in this study}

PFS are subject to the European Union (EU) Directive on Food Supplements $(2002 / 46 / \mathrm{EC})^{3}$ and, in the Netherlands, to the Herbal Preparations Decree in the Dutch Commodities Act. ${ }^{7}$ The EU Directive defines food supplements (including PFS) as "...foodstuffs the purpose of which is to supplement the normal diet and which are concentrated sources of nutrients or other substances with a nutritional or physiological effect, alone or in combination, marketed in dose forms, namely forms such as capsules, pastilles, tablets, pills and other similar forms, sachets of powder, ampoules of liquids, drop dispensing bottles and other similar forms of liquids and powders designed to be taken in measured small quantities".

According to the Herbal Preparations Decree in the Dutch Commodities Act, a herbal preparation is a herbal substance (a substance consisting of plant material), whether or not processed, which is intended to be used by humans, including herbal extracts. Culinary herb and spices, and cosmetics, food flavourings and medicines containing herbal substances do not fall within this definition.
The definition used for plant food supplement (PFS) in this study is a food supplement as defined by EU Directive 2002/46/ EC that contains (a) substance(s) consisting of plant material (also including material from e.g. algae, fungi or lichens), including extracts thereof. This definition includes food supplements that also contain vitamins, minerals or other substances besides herbal substances. Herbal products that are not food supplements, such as (traditional) herbal medicinal products, homeopathic products and herbal teas, were excluded.

\section{PFS consumption data from Dutch National Food Consumption Surveys (DNFCSs)}

Data collection. Data collected on PFS consumption in DNFCS 2007-2010 ${ }^{13}$ and DNFCS $2010-2012^{14}$ were used in the present study. The target population of the DNFCS 2007-2010 consisted of people aged 7 to 69 years living in the Netherlands. Pregnant and breast-feeding women, as well as institutionalized subjects were excluded. For practical reasons, only people with sufficient knowledge of the Dutch language were included. Respondents were selected from representative consumer panels of the market research agency GfK and a maximum of one person per household was included in the survey. Food consumption data were collected among 3819 participants over a 3-year period from March 2007 to April 2010. ${ }^{13}$

The target population of the DNFCS 2010-2012 consisted of community-dwelling men and women aged 70 years and older living in the Netherlands. Institutionalized people were excluded, as well as tube-fed or parenterally fed people, people with a high-intensity care package and people who were terminally ill. As for DNFCS 2007-2010, only people with sufficient knowledge of the Dutch language were included. The survey population was drawn from the population registered within 15 municipalities in the Netherlands, distributed to geographic region and address density. Food consumption data were collected among 739 participants from October 2010 to February 2012. ${ }^{14}$

In both surveys, food consumption data were collected by two non-consecutive $24 \mathrm{~h}$ dietary recalls per person (separated by 2 to 6 weeks). In the $24 \mathrm{~h}$ recalls not only foods and drinks, but also food supplements were registered. For each supplement the brand, type of supplement and dose was registered. The surveys covered all days of the weeks and all four seasons. An additional questionnaire was used to cover, amongst others, the frequency of use of food supplements. For each specific food supplement, the frequency of consumption during winter and the rest of the year over the preceding twelve months could be filled in. ${ }^{13,14}$ In DNFCS 2007-2010 the food frequency questionnaire provided a list of generic vitamin and mineral supplements and PFS could be listed as 'other supplements'. 'Other supplements' was defined as supplements other than those containing only vitamins, minerals and/or fatty acids, and it is assumed by the authors that many of the remaining 'other supplements' are PFS. In DNFCS 2010-2012, the list of generic supplements also included garlic, ginseng and ginkgo supplements. Other PDF could be listed as 'other supplements'. 
Data handling and data analyses. Based on the information from the food frequency questionnaires the percentage of PFS users was calculated for six age and gender subgroups (men and women aged 7 to 18 years, 19 to 69 years and 70 years and older). The data were analysed using SAS version 9.2 (SAS Institute Inc., Cary, NC, USA). The results were weighted for small deviances in sociodemographic factors compared to the general Dutch population in 2008 (DNFCS 2007-2010) and 2010 (DNFCS 2010-2012). Based on the information from the $24 \mathrm{~h}$ recalls, the most frequently consumed PFS in both surveys together were determined.

\section{PFS consumption survey}

The specific survey on PFS consumption was conducted in two phases in 2014. First, a screening survey was performed to estimate the percentage of users of PFS in eight different age and gender subgroups of the Dutch population (children aged 1-8 and 9-18 years, and women and men aged 19-50 years, 51-69 years and 70 years and older) and to select PFS users for the main survey. For children, no large differences in PFS consumption between boys and girls were expected, and therefore the subgroups for children were only based on age. The screening survey was followed by the main survey, which was conducted with a PFS user selection of the screened population, to obtain detailed information on PFS consumption characteristics in the different subgroups. The field research was conducted by the market research agency GfK among members of their panel between 1 October and 1 December 2014. The activities of GfK comply with national and EU data protection legislation. The authors received anonymised data from GfK.

Screening survey. The screening survey was performed among members of the online panel of the market research agency GfK, as part of the monthly online screening survey on a wide range of topics, between 1 and 15 October 2014. Based on the prevalence of PFS use in the Dutch population estimated on the basis of the DNFCSs, all 81729 members of the online panel aged 18 years and older were asked if they had used PFS during the preceding 12 months. Parents of children aged 1 to 18 years were asked to fill in the screening survey for their children as well. A detailed explanation of the definition of PFS was given (the questionnaire - in Dutch - can be obtained upon request). Participants could also indicate if they were not sure whether the products used were PFS. In that case, they were requested to provide details (name, brand, dose form) on the products used.

Main survey. The main survey was also conducted using an online questionnaire (the questionnaire - in Dutch - can be requested from the researchers). The target for the main survey was 100 respondents for each of the eight age and gender subgroups. Therefore, a representative sample of 199-500 PFS users was selected per subgroup, taking into account the expected response rate for the particular age and gender groups. The main survey was conducted between 31 October and 1 December 2014. The online questionnaire was based on the questionnaire developed in the PlantLIBRA project ${ }^{12}$ and adjusted for the current research questions and on-line assessment. The questionnaire consisted of 13 detailed questions for each PFS used by the participant in the preceding 12 months (amongst others on the name, brand, dose form, purchase location and the herbal ingredients of the PFS, the frequency and amount used and reasons for use). Regarding the herbal ingredients, 32 frequently used PFS ingredients were listed by their common Dutch name and their scientific name. In some cases, e.g. for Echinacea spp., Ginseng spp., algae and kelp/seaweed, the focus was on the entire genus or group to promote recognition by the participants. Open lines were provided to fill out names of other herbal ingredients. Instructions were given on how to distinguish PFS from (homeopathic) medicines, vitamin and mineral supplements, herbal teas and herbs and spices used in dishes. The questionnaire also contained general questions, covering for instance the health status of the participants and the concomitant use of other food supplements and medicinal products. At the end of the questionnaire, there was a possibility for the participants to upload pictures of the PFS used.

\section{Data handling and data analysis}

Screening survey. The data were analysed using SAS version 9.2 (SAS Institute Inc., Cary, NC, USA). For participants that indicated that they were not sure whether the products used were PFS, the authors determined, based on the provided details (name, brand, dose form) of the products used, whether these respondents should be classified as PFS user or not. Respondents for which this was not possible based on the (lack of) information provided were excluded from further analyses and from sample selection for the main survey. The results of the screening were weighted for the background characteristics age, gender, education, size of household, geographical region, internet use, social class and degree of urbanization to obtain results that are optimally representative of the Dutch population (using the Golden Standard from 2013 of the Dutch Center for Information Based Decision Making \& Marketing Research (MOA)).

Main survey. The data were analysed using SAS version 9.2 (SAS Institute Inc., Cary, NC, USA). Based on the name, brand, dose form, herbal ingredients and the uploaded pictures, the correctness of the herbal ingredients of all reported PFS was checked by the authors using label information and/or internet, and adjusted if needed. Botanicals described as 'fruit extract' or 'vegetable extract' were registered as 'unknown fruit and/or vegetable extract' because it was not possible to obtain information on the origin. Different species of mushrooms, algae and seaweed were registered as, respectively, 'mushrooms', 'algae' and 'kelp/seaweed', because detailed information on origin was not available for a large part of the supplements. Also, each PFS was classified as a single ingredient or a multi ingredient food supplement. PFS for which the herbal ingredients could not be verified were not included in the analyses. Reported PFS that did not meet the definition of a PFS and respondents that were judged not to have used at least one supplement that met the definition of PFS were excluded from the analyses. 
Table 1 Percentage of users of 'other supplements'a during the preceding year in the food frequency questionnaire of Dutch National Food Consumption Survey 2007-2010 and Dutch National Food Consumption Survey 2010-2012, weighted for small deviances in sociodemographic factors compared to the Dutch population in 2008 and 2010, respectively

\begin{tabular}{lcrc}
\hline Gender and age (years) & \multicolumn{1}{l}{ \% } & $\begin{array}{l}\text { \% Users of } \\
\text { 'other supplements' }\end{array}$ \\
\hline Boys & $7-18$ & 856 & 2.8 \\
Girls & $7-18$ & 857 & 2.0 \\
Men & $19-69$ & 1055 & 4.6 \\
Women & $19-69$ & 1051 & 10.5 \\
Men & $70+$ & 373 & 8.9 \\
Women & $70+$ & 366 & 13.9
\end{tabular}

${ }^{a}$ Other supplements are food supplements other than those containing only vitamins, minerals and/or fatty acids. It is assumed by the authors that many of these are plant food supplements.

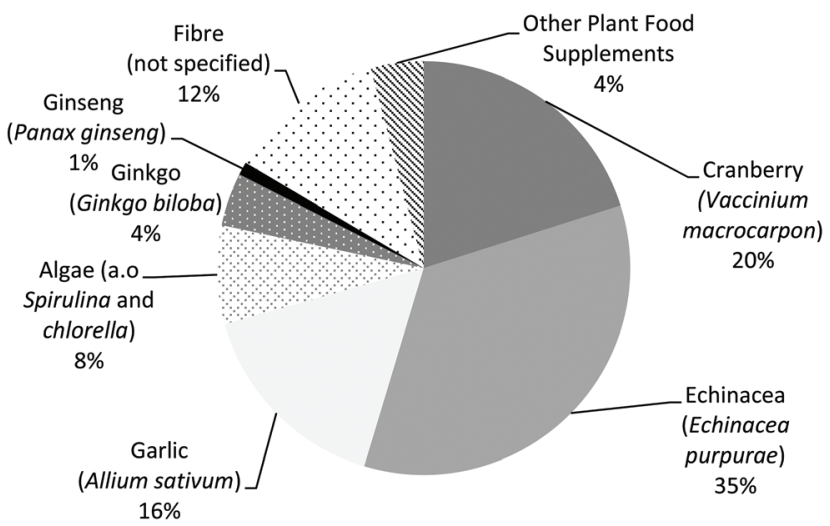

Fig. 1 Botanicals in the plant food supplements reported to be used in the $24 \mathrm{~h}$ dietary recalls in the Dutch National Food Consumption Survey 2007-2010 and Dutch National Food Consumption Survey 2010-2012.

\section{Results}

\section{Use of PFS based on the Dutch National Food Consumption Surveys (DNFCSs)}

Based on the food frequency questionnaires of the DNFCSs, the percentage of respondents that reported the use of 'other supplements' in the preceding year ranged from 2.0 to $13.9 \%$ (Table 1). The lowest percentages were reported in children (2.8\% for boys and $2.0 \%$ for girls) and the percentage increased with age. In the $24 \mathrm{~h}$ dietary recalls in both DNFCSs, consumption of PFS containing echinacea (Echinacea purpurea) was most frequently reported, followed by cranberry (Vaccinium macrocarpon), garlic (Allium sativum) and fibre (plant source could not be specified) (Fig. 1).

\section{Response in PFS consumption survey}

For the PFS screening survey, 81729 adults were invited and 55266 (68\%) responded. These adults also filled in the screening survey for in total 21242 children in the age of 1-18 years.

Six children were excluded since details on their age and gender were missing. The total number of completed questionnaires was 76502 (Table 2). In $6.4 \%$ of the completed questionnaires, the respondents indicated that they were not sure whether the products that they or their children had used were indeed PFS. By using the information provided by the respondents on the name, brand and dose form of these products, the authors were able to conclude on the use of PFS for most of these respondents. Of the products that appeared not to be PFS, about 70-80\% were food supplements with (a) vitamin(s) and/or mineral(s) and about $7-8 \%$ were medicines. The remaining products were normal foods and medical devices. For 1402 questionnaires $(1.8 \%$ of the completed questionnaires) it was not clear for the authors if the products used were PFS. These were excluded for further analyses and the subjects were excluded in the sample for the main survey. After these corrections, the total number of completed questionnaires of the screening phase was 75100.

Table 2 Response of invited participants in screening survey and main survey into use of plant food supplements (PFS)

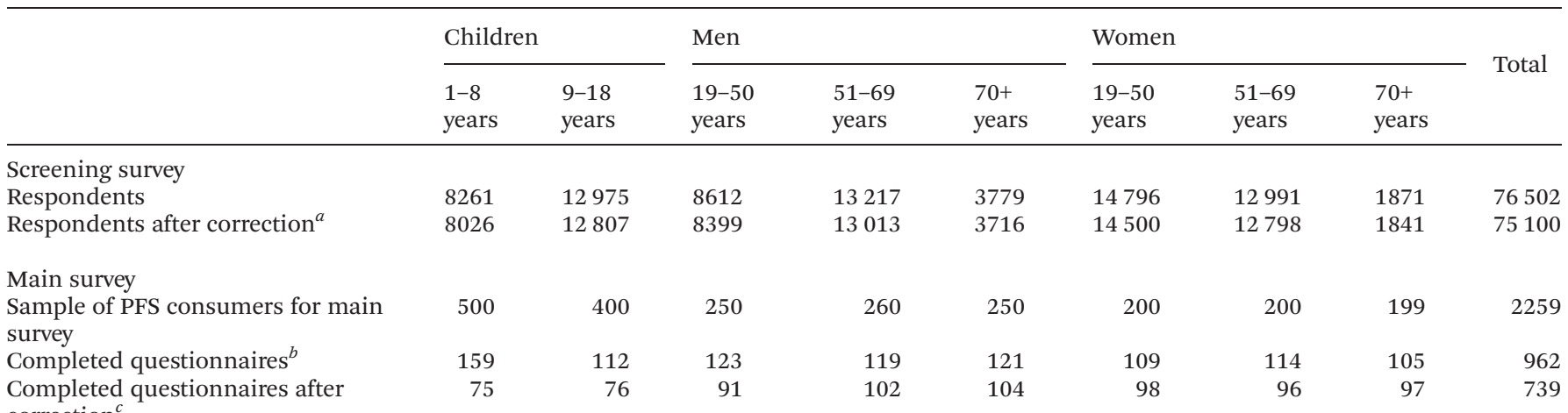
correction $^{c}$

\footnotetext{
${ }^{a}$ Corrected by excluding the respondents who indicated not to be sure if the products they used were PFS and for which a confirmation regarding the PFS status could not be obtained by the investigators. ${ }^{b}$ Excluding non-respondents $(n=316)$, respondents that indicated that they did not use PFS during the preceding 12 months $(n=609)$ and respondents that did not complete the questionnaire $(n=372) .{ }^{c}$ Corrected by excluding the respondents for which none of the reported products met the definition of PFS.
} 
Table 3 Percentage of self-reported plant food supplement (PFS) users based on the screening study, weighted for gender, age, education, size of household, internet use, geographical region, degree of urbanization and socio-economic factors

\begin{tabular}{lcrc}
\hline Gender and age (years) & \multicolumn{1}{c}{$N^{a}$} & \% Users of PFS \\
\hline Children & $1-8$ & 8026 & 14 \\
Children & $9-18$ & 12807 & 11 \\
Men & $19-50$ & 8399 & 11 \\
Women & $19-50$ & 14500 & 18 \\
Men & $51-69$ & 13013 & 9 \\
Women & $51-69$ & 12798 & 17 \\
Men & $70+$ & 3716 & 9 \\
Women & $70+$ & 1841 & 15
\end{tabular}

${ }^{a}$ Number of subjects with correctly filled in screening questionnaire.
For the main survey, the target was 100 subjects for each age and gender group. The number of completed questionnaires per group varied from 105 to 159 subjects. After exclusion of the subjects for whom none of the reported PFS met the definition of PFS, 75-104 completed questionnaires were left in the different age and gender groups. The reported PFS that did not meet the definition mentioned above were for instance food supplements containing only vitamins, minerals and/or other ingredients (other than botanicals), normal foods, medicines and/or medical devices. In total, $739 \mathrm{com}$ pleted questionnaires were included in the analyses (Table 2).

\section{Use of PFS and user characteristics based on PFS consumption survey}

Based on the screening survey, the percentage of self-reported PFS users ranged from 9 to $18 \%$ in the different age and

Table 4 Sociodemographic characteristics of self-reported plant food supplements (PFS) users versus non-users based on the screening survey, weighted for gender, age, education, size of household, social class, internet use, region and urbanisation ${ }^{a}$

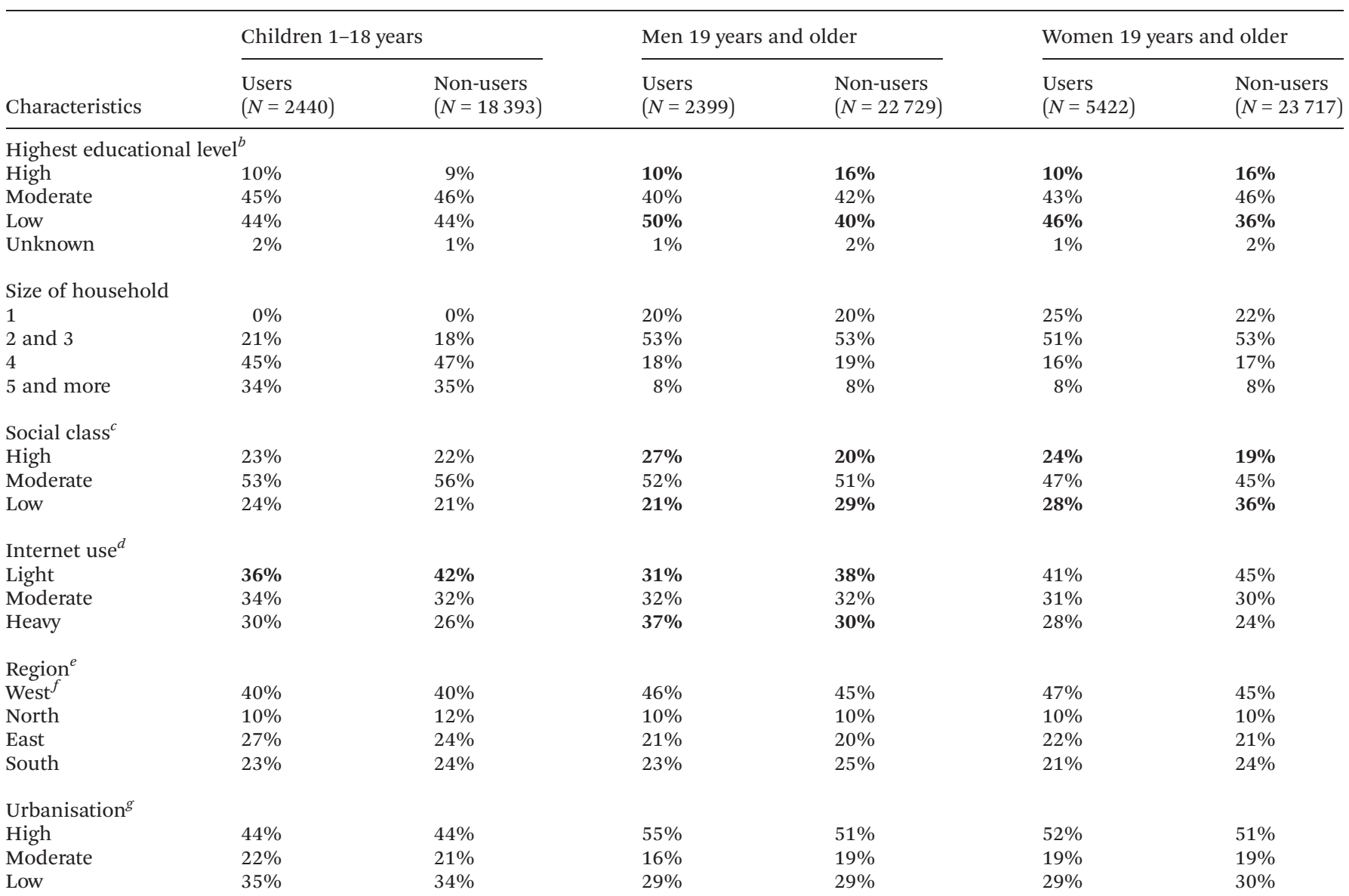

${ }^{a}$ Percentages are rounded up. Percentages that differ for $\geq 5 \%$ between users and non-users of the same age group are printed in bold. ${ }^{b}$ Low $=$ primary school, lower vocational, low or intermediate general education; moderate = intermediate vocational education and higher general education; high = higher vocational education and university. For children, the highest educational level of the parents is reported. ${ }^{c}$ Based on a combination of the profession of the respondent and the educational level of the main costs earner of the household according to the Golden Standard of the Dutch Center for Information Based Decision Making \& Marketing Research (MOA). High = A; moderate = B1, B2 and C; low = D. ${ }^{d}$ Light $=0-4 \mathrm{~h}$ per week, moderate $=5-13 \mathrm{~h}$ per week, heavy $=\geq 14 \mathrm{~h}$ per week. ${ }^{e}$ For 4 respondents, no details on region are available. ${ }^{f}$ The Western region was separately sampled for 3 big cities (Amsterdam, Rotterdam and The Hague) including 6 satellite towns and the remainder of the region. ${ }^{g}$ Urbanisation: High $=>1500$ addresses per $\mathrm{km}^{2}$, moderate $=1000-1500$ addresses per km ${ }^{2}$, low $=<1000$ addresses per $\mathrm{km}^{2}$. 
gender groups, with the lowest percentage of PFS users in men aged 51-69 years (9\%) and men aged $70+$ years (9\%), and the highest percentage of PFS users in women aged 19-50 years (18\%) and women aged 51-69 years (17\%) (Table 3). Table 4 shows the sociodemographic characteristics of self-reported users and non-users of PFS. PFS users tended to have more often a low educational level but a high social class (social class is based on a combination of the profession of the respondent and the educational level of the main costs earner of the household). Also, PFS users were more often heavy internet users ( $\geq 14$ h per week) compared to non-users.

\section{Characteristics of PFS use based on PFS consumption survey}

Most PFS users reported the use of one type of PFS during the preceding 12 months (children 87\%, men 64\% and women $58 \%$ ), whereas about $10 \%$ of the children and one quarter of the adult PFS users indicated to have used two types of PFS (Table 5). The maximum number of type of PFS reported to be used was seven PFS by one woman. More than one out of three reported the additional use of other food supplements during the preceding 12 months. For most PFS, the users indicated that they were used on a daily basis (910 out of 1114 PFS, $82 \%)$, and for 354 of them (39\%), the users indicated that they have used them in this frequency during the entire preceding 12 months. The PFS-users described their health mainly as 'very well' and 'well' ( $81 \%$ of the children, $69 \%$ of the men and $60 \%$ of the women), whereas only $4 \%$ of the children, $6 \%$ of the men and $9 \%$ of the women described their perceived health as 'bad' and only $1 \%$ of the women as 'very bad'. Improvement of the immune system/defence system was the main reason for the use of PFS in children (31\%), men (17\%) and women (19\%). Improvement of the energy level was the second most important reason for men and the third most important reason for children (with flu/cold as second reason) and women (with improvement of the urinary tract as second reason). The concomitant use of medicinal products was reported by about $20 \%$ of the children and $58 \%$ of the adults. Homeopathic medicines were used by about $20 \%$ of the children, $15 \%$ of the men and $25 \%$ of the women. About $20 \%$ of the children were treated by a complementary or alternative health care professional (for instance a chiropractor or acupuncturist) and about $40 \%$ of the men and $46 \%$ of the women (Table 5). Most PFS were purchased in a drugstore (42\%), followed by internet/web shop (21\%) and health shop/vitamin store $(21 \%)$. Only $4 \%$ of the reported PFS were bought in a pharmacy (Fig. 2). Most products were used on own initiative (37\%), followed by recommendations from friends/relatives (16\%; Fig. 3).

Product characteristics of PFS used based on PFS consumption survey. In total, 1738 PFS were reported by the respondents. After removal of products that did not meet the definition of PFS (445 products, 26\%) and PFS for which the herbal ingredients could not be verified (178 PFS, 10\%) 1114 PFS (64\%) were left. It is estimated that about 600 different products were used of approximately 250 brands (Table 6). It was not possible to determine absolute figures, because this information was not available for all PFS. Most PFS used were in the form of pills/tablets/lozenges $(53 \%)$ or capsules $(30 \%)$, followed by PFS in liquid form (drops/syrup 10\%). Roughly half of the PFS used were single ingredient food supplements, the other half were multi ingredients food supplements, con-

Table 5 Use of other food supplements, medicines and homeopathic medicines and complementary or alternative health care and perceived health among plant food supplement (PFS) users

\begin{tabular}{|c|c|c|c|}
\hline & Children $(N=151)$ & $\operatorname{Men}(N=297)$ & Women $(N=291)$ \\
\hline 1 & $87 \%$ & $64 \%$ & $58 \%$ \\
\hline 4 or more & $0 \%$ & $5 \%$ & $6 \%$ \\
\hline \multicolumn{4}{|l|}{ Top 5 reasons of use } \\
\hline 3 & Energy $(9 \%)$ & Heart/blood circulation (7\%) & Energy ( $8 \%)$ \\
\hline 4 & Relaxing $(6 \%)$ & General health $(6 \%)$ & Digestive function (7\%) \\
\hline 5 & General health $(6 \%)$ & Digestive function (6\%) & Other $(7 \%)$ \\
\hline \multicolumn{4}{|l|}{ Use of } \\
\hline Other food supplements & $34 \%$ & $36 \%$ & $38 \%$ \\
\hline Medicines & $21 \%$ & $58 \%$ & $58 \%$ \\
\hline \multicolumn{4}{|l|}{ Perceived health } \\
\hline Very well & $30 \%$ & $12 \%$ & $7 \%$ \\
\hline Well & $51 \%$ & $57 \%$ & $52 \%$ \\
\hline Neutral & $15 \%$ & $25 \%$ & $32 \%$ \\
\hline Bad & $4 \%$ & $6 \%$ & $9 \%$ \\
\hline Very bad & $0 \%$ & $0 \%$ & $1 \%$ \\
\hline
\end{tabular}




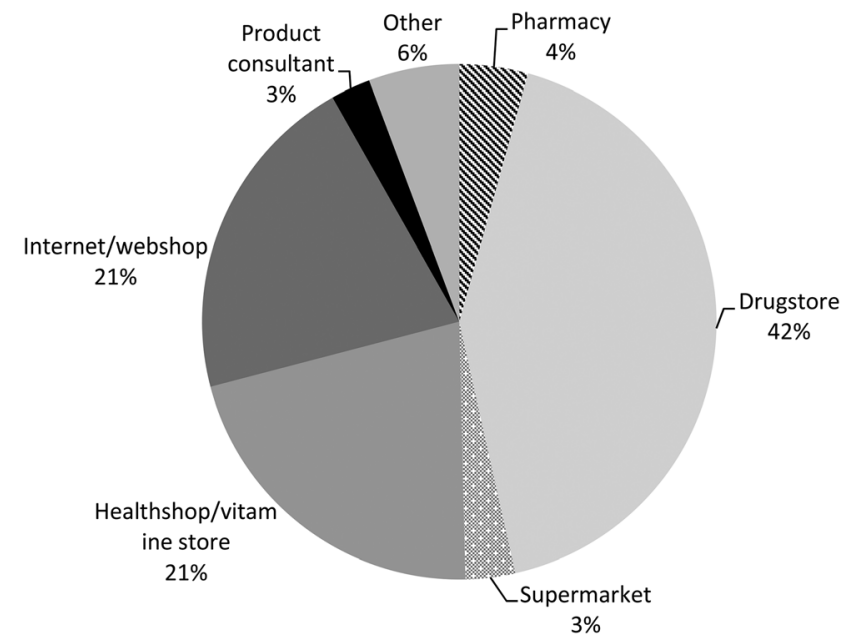

Fig. 2 Purchase locations of plant food supplements ( $n=1159$; respondents could fill in more than one location per plant food supplement). Pharmacy (in Dutch 'apotheek'): A store that sells medicines and foods for special medical purposes on prescription as well as over-thecounter-medicines, medicinal products and food supplements. Drugstore (in Dutch 'drogist'): A shop that sells a.o. over-the-countermedicines (but not medicines on prescription), food supplements, dietetic foods as well as personal care products. Healthshop/vitamin store: A shop that sells a.o. 'natural' foods, dietetic foods, and supplements, together with all other kinds of food related to a healthy/healthier life style.

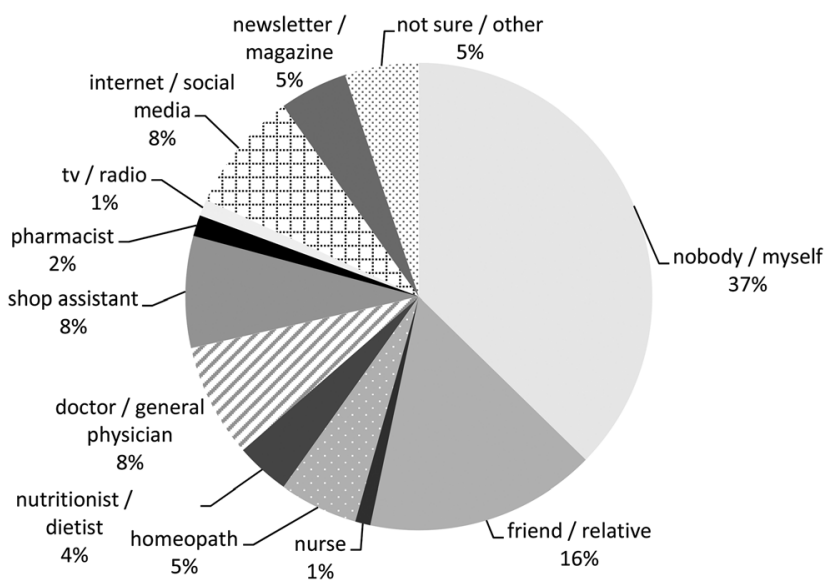

Fig. 3 Who recommended the use of the plant food supplements $(n=$ 1230; respondents could fill in more than one answer per plant food supplement)?

taining more than one botanical and/or a combination of one or more botanical(s) with one or more vitamins, minerals or other active ingredients. Several of the PFS used contained a herbal blend or extracts of fruit and vegetables containing many different botanicals. The maximum number of botanicals per product was 54 .

These PFS contained altogether 345 different botanicals. It should be noted that the actual number of consumed botanicals is even larger, because some botanicals were grouped
Table 6 Characteristics of plant food supplements (PFS) reported in the survey $(n=1114)$

Total number of different products Approximately

Total number of botanicals 600

Total number of single ingredi supplements used

Total number of multi ingredient food

525 supplements used

Maximum number of botanicals per product Number of brands

589

54

Approximately 250

Dose form of PFS used

Capsules (softgels, pearls, hard capsules)

Pills/tablets/lozenges

Liquid (extract, syrups, drops)

Sachets/powder

Ampoules

Others

Unknown

$$
\begin{aligned}
& 330(30 \%) \\
& 590(53 \%) \\
& 116(10 \%) \\
& 38(3 \%) \\
& 25(2 \%) \\
& 13(1 \%) \\
& 2(0 \%)
\end{aligned}
$$

(unknown fruit and/or vegetable extract, mushrooms, algae and kelp/seaweed). Table 7 lists the botanicals that were present in at least 5 of the 1114 PFS. The most used botanicals (in >100 PFS) were echinacea (Echinacea purpurea), ginkgo (Ginkgo biloba), cranberry (Vaccinium macrocarpon), ginseng (Panax ginseng) and algae (such as species belonging to the genus Spirulina or Chlorella), followed (in $>50$ PFS) by citrus bioflavonoids (no detailed information on the origin available), grape (stone) (Vitis vinifera), valerian (Valeriana officinalis), rose hip (Rosa canina), garlic (Allium sativum), green tea (Camellia sinensis) and acerola (Malpighia spp.).

Echinacea (Echinacea purpurea) belonged to the four most frequently used botanicals in all eight age and gender groups. Cranberry (Vaccinium macrocarpon) and algae (such as species belonging to the genus Spirulina or Chlorella) were in the top 10 of the most used botanicals in all groups, except for young children (aged 1 to 8 years) (Table 8). Ginkgo (Ginkgo biloba) and ginseng (Panax ginseng) both belonged to the three most frequently used botanicals in men and women aged 51-69 years and 70 years and more. In most cases, these two botanicals were used in multivitamins marketed for people aged 50+, $60+$ or $65+$. For children aged 1 to 18 years, roughly $60 \%$ of the PFS used were PFS containing multiple ingredients, mainly multivitamin/mineral supplements with one or more botanical ingredients. About $20 \%$ of the PFS used were single PFS with echinacea (Echinacea purpurea), and the remaining $20 \%$ of the PFS used were single PFS containing other botanicals.

\section{Discussion and conclusion}

The current paper describes the consumption of PFS in various age and gender subgroups in the Netherlands. First, data collected on PFS consumption in recent DNFCSs were analysed. Thereafter, a specific PFS consumption survey among 75100 respondents (screening survey) and 739 users of PFS (main survey) was conducted. Based on the screening 


\begin{tabular}{|c|c|c|c|c|}
\hline Botanical $(N)$ & Botanical $(N)$ & Botanical $(N)$ & Botanical $(N)$ & Botanical $(N)$ \\
\hline Echinacea (175) & Black currant (25) & Siberian ginseng (14) & Cat’s whisker (9) & Caraway (6) \\
\hline Echinacea purpurea (L.) Moench & Ribes nigrum L. & $\begin{array}{l}\text { Eleutherococcus senticosus } \\
\text { (Rupr. \& Maxim.) Maxim. }\end{array}$ & Orthosiphon stamineus Benth. & Carum carvi $\mathrm{L}$. \\
\hline Ginkgo (111) & St John's wort (24) & Blackberry (14) & Psyllium (9) & Clove (6) \\
\hline Ginkgo biloba $\mathrm{L}$. & Hypericum perforatum $\mathrm{L}$. & Rubus fruticosus & Plantago spp. & $\begin{array}{l}\text { Syzygium aromaticum (L.) Merr. \& } \\
\text { L. M. Perry }\end{array}$ \\
\hline Cranberry (106) & Beetroot (24) & Chamomile (14) & Sage (9) & Maca (Peruvian Ginseng) (6) \\
\hline Vaccinium macrocarpon Aiton & Beta vulgaris $\mathrm{L}$. & Matricaria chamomilla L. & Salvia officinalis $\mathrm{L}$. & Lepidium meyenii Malp. \\
\hline Ginseng (105) & Saw palmetto (berry) (23) & Pollen (14) & Horsetail (8) & Monk's pepper (6) \\
\hline Panax ginseng C.A. Mey. & $\begin{array}{l}\text { Serenoa repens (W. Bartram) } \\
\text { Small }\end{array}$ & & Equisetum arvense $\mathrm{L}$. & Vitex agnus-castus $\mathrm{L}$. \\
\hline Algae (102) & Fennel (22) & Rosemary (14) & Birch (8) & Pau d'arco (6) \\
\hline e.g. Spirulina and Chlorella & Foeniculum vulgare Mill. & Rosmarinus officinalis $\mathrm{L}$. & Betula spp. & Tabebuia spp. \\
\hline Citrus bioflavonoids (80) & Blueberry (22) & Devil's claw (13) & Mango (8) & Buckthorn (6) \\
\hline & Vaccinium myrtillus L. & $\begin{array}{l}\text { Harpagophytum procumbens } \\
\text { (Burch.) DC. ex Meisn. }\end{array}$ & Mangifera indica $\mathrm{L}$. & Frangula spp. \\
\hline Grape and Grape stone (70) & Lemon balm (22) & Hibiscus (13) & Peach $(8)$ & Star of Bethlehem (6) \\
\hline Vitis vinifera $\mathrm{L}$. & Melissa officinalis $\mathrm{L}$. & Hibiscus spp. & Prunus persica (L.) Batsch & Ornithogalum umbellatum $\mathrm{L}$. \\
\hline Valerian (67) & Milk thistle (22) & Couch grass (13) & Propolis (8) & Brewer's yeast (5) \\
\hline Valeriana officinalis $\mathrm{L}$. & Silybum marianum (L.) Gaertn. & $\begin{array}{l}\text { Agropyron repens (L.) Gould ssp. } \\
\text { repens }\end{array}$ & & Saccharomyces cerevisiae \\
\hline Rose hip (65) & Oat (21) & Olive (11) & Rhubarb (8) & Clematis (5) \\
\hline Rosa canina $\mathrm{L}$. & Avena sativa $\mathrm{L}$. & Olea europea $\mathrm{L}$. & Rheum palmatum $\mathrm{L}$. & Clematis vitalba $\mathrm{L}$. \\
\hline Garlic (58) & Wheat (21) & Lemon (11) & Celery (8) & Pea (5) \\
\hline Allium sativum $\mathrm{L}$. & Triticum spp. & Citrus $\times$ limon (L.) Burm. f. & Apium graveolens $\mathrm{L}$. & Pisum sativum $\mathrm{L}$. \\
\hline Green tea (57) & Evening primrose (20) & Mushroom (11) & Echinacea (8) & Fenugreek (5) \\
\hline Camellia sinensis (L.) Kuntze & Oenothera biennis $\mathrm{L}$. & & $\begin{array}{l}\text { Echinacea angustifolia DC. } \\
\text { Apricot ( } 7 \text { ) } \\
\text { Prunus armeniaca L. }\end{array}$ & Trigonella foenum-graecum $\mathrm{L}$. \\
\hline Acerola (54) & Apple (20) & Papaya (11) & Pineapple (7) & Raspberry (5) \\
\hline Malpighia spp. & Malus domestica Borkh. & Carica papaya $\mathrm{L}$. & Ananas comosus (L.) Merr. & Rubus idaeus $\mathrm{L}$. \\
\hline Kelp/Sea weed (43) & $\begin{array}{l}\text { Orange (20) } \\
\text { Citrus sinensis (L.) Osbeck }\end{array}$ & $\begin{array}{l}\text { English plantain (11) } \\
\text { Plantago lanceolata L. }\end{array}$ & $\begin{array}{l}\text { Astralagus (7) } \\
\text { Astragalus spp. }\end{array}$ & $\begin{array}{l}\text { Rockrose (5) } \\
\text { Helianthemum nummularium (L.) Mill. }\end{array}$ \\
\hline
\end{tabular}


Table 7 (Contd.)

\begin{tabular}{|c|c|c|c|c|}
\hline Botanical $(N)$ & Botanical $(N)$ & Botanical $(N)$ & Botanical $(N)$ & Botanical $(N)$ \\
\hline Nettle (41) & Watercress (20) & Thyme (11) & Skullcap (7) & Juniper (5) \\
\hline Urtica dioica $\mathrm{L}$. & Nasturtium officinale W. T. Aiton & Thymus vulgaris $\mathrm{L}$. & Scutellaria lateriflora $\mathrm{L}$. & Juniperus communis L. \\
\hline Turmeric (38) & Cat’s claw (19) & Guarana (10) & Cauliflower (7) & Plum (5) \\
\hline Curcuma longa $\mathrm{L}$. & Uncaria tomentosa (Willd.) DC, & Paullinia cupana Kunth & $\begin{array}{l}\text { Brassica oleracea L. var. botrytis } \\
\text { L. }\end{array}$ & Prunus spp. \\
\hline Alfalfa (31) & Hawthorn (19) & Angelica root (10) & Kale (7) & Cabbage (5) \\
\hline Medicago sativa $\mathrm{L}$. & Crataegus spp. & Angelica spp. & Brassica oleracea $\mathrm{L}$. & Brassica spp. \\
\hline Goldenrod (31) & Licorice (19) & Dong quai (10) & Boswellia (7) & Unknown vegetables or fruits extrac \\
\hline Solidago virgaurea $\mathrm{L}$. & Glycyrrhiza glabra $\mathrm{L}$. & Angelica sinensis (Oliv.) Diels & Boswellia spp. & \\
\hline Spinach (31) & Elder (18) & Pomegranate (10) & Centaury (7) & Oregano (5) \\
\hline Spinacia oleracea $\mathrm{L}$. & Sambucus spp. & Punica granatum $\mathrm{L}$. & Centaurium spp. & Origanum spp. \\
\hline Carrot (31) & Tomato (17) & Mistletoe (10) & Garcinia cambogia (7) & Popular (5) \\
\hline Daucus carota L. & Solanum lycopersicum $\mathrm{L}$. & Viscum album $\mathrm{L}$. & Garcinia cambogia Desr. & Populus spp. \\
\hline Aloe (30) & Broccoli (16) & Pear (10) & Cinnamon (7) & Red yeast rice (5) \\
\hline Aloe vera (L.) Burm. f. & Brassica oleracea $\mathrm{L}$. & Pyrus spp. & Cinnamomum spp. & Monascus purpureus \\
\hline Passion flower (30) & Pumpkin seed (16) & California poppy (10) & Senna $(7)$ & Himalayan balsam (5) \\
\hline Passiflora incarnata $\mathrm{L}$. & Cucurbita pepo L. & Eschscholzia californica Cham. & Senna alexandrina Mill. & Impatiens glandulifera Arn. \\
\hline Bearberry (30) & Linseed (15) & Peppermint (9) & Asparagus (6) & Rice (5) \\
\hline $\begin{array}{l}\text { Arctostaphylos uva-ursi (L.) } \\
\text { Spreng. }\end{array}$ & Linum usitatissimum $\mathrm{L}$. & Mentha piperita $\mathrm{L}$. & Asparagus officinalis $\mathrm{L}$. & Oryza sativa $\mathrm{L}$. \\
\hline Pepper (28) & Black cohosh (15) & (Wild) strawberry (9) & Cascara (6) & Schisandra (5) \\
\hline Piper nigrum L. & Actaea racemosa $\mathrm{L}$. & Fragaria spp. & Frangula purshiana (DC.) A. Gray & Schisandra chinensis (Turcz.) Baill. \\
\hline Parsley (28) & Cherry (15) & Acai $(9)$ & Cayenne pepper (6) & \\
\hline Petroselinum crispum (Mill.) Fuss & Prunus spp. & Euterpe oleracea Mart. & Capsicum annuum $\mathrm{L}$. & \\
\hline Ginger (26) & Dandelion (15) & Barley (9) & Gotu kola (6) & \\
\hline Zingiber officinale Roscoe & Taraxacum officinale F. H. Wigg. & Hordeum vulgare $\mathrm{L}$. & Centella asiatica (L.) Urb. & \\
\hline Soy/soy isoflavones (25) & Artichoke (14) & Hop (9) & Grapefruit (6) & \\
\hline Glycine $\max (\mathrm{L}$.$) Merr.$ & Cynara scolymus $\mathrm{L}$. & Humulus lupulus $\mathrm{L}$. & Citrus paradisi Macfad. & \\
\hline
\end{tabular}




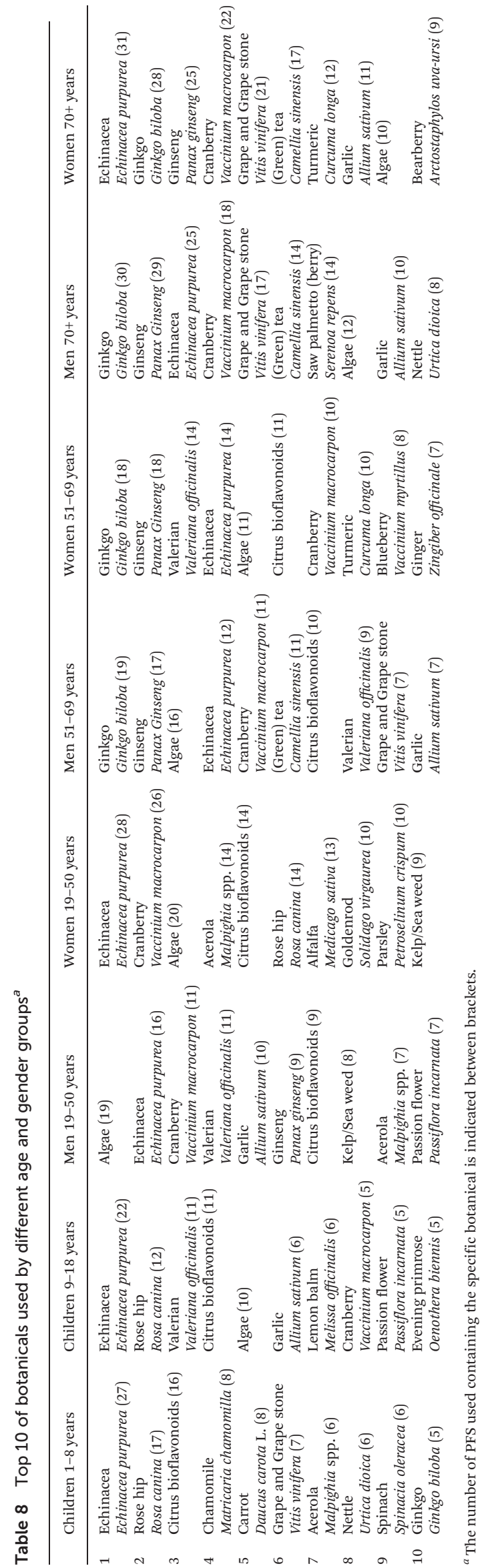

urvey, the prevalence of PFS users in the Dutch population was approximately $10 \%$ for men, $17 \%$ for women and $13 \%$ for children. The PFS used are very diverse, with approximately 600 different PFS of about 250 brands, containing a wide range of botanicals (>345 species). The most frequently used botanicals were echinacea (Echinacea purpurea), ginkgo (Ginkgo biloba), cranberry (Vaccinium macrocarpon), ginseng (Panax ginseng) and algae.

The prevalences of PFS users based on the PFS consumption survey were higher, especially for children, than those estimated based on the results obtained based on the FFQs in the DNFCSs (range 2-14\% among the different age-gender groups). ${ }^{13,14}$ This difference may partly be explained by a rise in the use of PFS over the last years. Another explanation may be a difference in classification of PFS between the studies due to different study design and purpose. The PFS consumption survey showed that more than half of the PFS used by children were supplements containing vitamins and/or minerals which also contained one or more botanicals. The aim of the questions on food supplement use in the DNFCSs was mainly to obtain information on the intake of vitamins, minerals and fish fatty acids. In the DNFCSs, these types of food supplements have therefore been registered as (multi)vitamin and/or mineral supplements, without annotation of a botanical ingredient. This may have led to underestimation of PFS use, especially by children. On the other hand, it was assumed that all "other supplements" reported in the FFQs of the DNFCSs were PFS, which has probably led to a slight overestimation. Because of the rise in PFS use in the last years the ongoing DNFSCs include more detailed questions on PFS use. The results of the current study will be used to further improve the questions on PFS use in the DNFSCs. Despite these limitations, it can be concluded that the prevalence of PFS use in the Netherlands is within the range previously reported for adults in six other European countries (9.6-22.7\%, overall prevalence $18.8 \%{ }^{12}$ ).

The results of the PFS consumption showed that it was difficult for respondents to judge whether the consumed products were PFS. In the screening survey, about $6 \%$ of the respondents answered that they were not sure about the products they had used. In addition, about $27 \%$ of the selfreported PFS users of the screening study that were selected for the main survey inconsistently answered on the first question of the main survey that they did not use a PFS in the preceding 12 months. This unexpected contradictory result indicates that the topic of the survey was difficult for participants. Also, many presumed PFS products (26\%) reported by respondents in the main survey were actually not PFS. The products that were incorrectly classified as PFS were mainly food supplements with vitamins, minerals and other ingredients (other than botanicals). In several cases, the participants have classified these food supplements as PFS due to the flavourings (for instance banana, orange or anise extract) of these food supplements. Also traditional herbal medicinal products (THMPs), regular herbal medicinal products and homeopathic products were sometimes reported as PFS by respondents. Several respondents from the main study had to be excluded 
from further analysis, because none of the products reported were PFS. This was the reason that the target of 100 for each age and gender subgroup was not reached for all groups (range: 75-104 correctly completed questionnaires per subgroup). Due to the difficulties the respondents had with the correct classification of the products they used, the differences observed between characteristics of PFS users and non-users should be interpreted with care.

From the botanicals that were mostly used (in >50 PFS, Table 6), ginkgo (Ginkgo biloba), ginseng (Panax ginseng), valerian (Valeriana officinalis) and echinacea (Echinacea purpurea) were also among the ten most frequently used botanicals in the PlantLibra study, ${ }^{12}$ whereas the other mostly used botanicals were quite different. Evening primrose (Oenothera biennis) and artichoke (Cynara scolymus) are for instance listed in the top 3 of the PlantLibra study, but ranked respectively as number 52 and 37 in the current study. This is in line with the finding in the PlantLibra study that the top list of botanicals contained in PFS for each single country complied little with the overall ranking of the results of the six countries together.

To our knowledge, this is the first study that provides information on the PFS use by children in Europe. The results show that the prevalence of PFS use increases with age, and that the types of PFS used differ largely between children and adults. Most of the children (87\%) that participated in the main study had used one PFS in the preceding 12 months. PFS containing echinacea (Echinacea purpurea) were mostly used, followed by PFS containing rose hip (Rosa canina) and citrus bioflavonoids. The main reason for use of the PFS as indicated by the participants was to improve the defence system/immune system (31\%) or because of flu or cold (12\%). This is also reflected in the type of PFS used, because children used mainly multivita$\mathrm{min} / \mathrm{mineral}$ supplements with one or more botanical ingredients, followed by single PFS with Echinacea (Echinacea purpurea).

The frequently used herbs echinacea (Echinacea purpurea), ginkgo (Ginkgo biloba), ginseng (Panax ginseng), grape (stone) (Vitis vinifera) and valerian (Valeriana officinalis) are ingredients of registered regular and traditional herbal medicinal products and/or homeopathic products in the Netherlands, ${ }^{15}$ and tablets containing cranberry (Vaccinium macrocarpon) are on the market as PFS and as medical devices. Although the difference between these type of products is apparently not always clear for consumers, the legal requirements related to the safety, quality and effectiveness of these products differ. ${ }^{4}$ Consumers may therefore not be aware of these different legal requirements and thereby possible differences in product composition.

About $20 \%$ of the children and $60 \%$ of the adults from the main survey indicated the concomitant use of medicinal products on a regular basis in the preceding year. This could pose a risk on adverse herb-drug interactions. Interaction between St. John's wort (Hypericum perforatum) and drugs metabolized by CYP3A4 is a well-known example. ${ }^{16}$ Also, there are indications that the botanicals ginkgo (Ginkgo biloba), garlic (Allium sativum) and ginseng (Panax ginseng) may interact with anticoagulants. ${ }^{17,18}$ In a follow up study, the available data can be further analysed to see if potentially harmful combinations are reported.

In conclusion, the current study provided detailed insight in the use of PFS in the Dutch population, including children. The study showed that the national food consumption surveys can be used to monitor the prevalence of PFS use and the consumption of frequently used PFS, but that for detailed information on the wide range of PFS used, a specific PFS consumption study is needed. PFS are widely used by the Dutch population, and it appeared to be difficult for consumers to make a distinction between PFS and other products containing botanicals on the market having other legal requirements with respect to safety, quality and efficacy. This emphasises the need to evaluate the potential risks associated with PFS consumption in the Netherlands, including potential herb-drug interactions. The data collected in this study are of great value to assess these risks.

\section{Conflicts of interest}

There are no conflicts to declare.

\section{Acknowledgements}

The authors would like to thank Jolanda van Oirschot and Marcel Temminghoff from GfK and Alicia Garcia-Alvarez (Fundación para la Investigación Nutricional, Barcelona Science Park, University of Barcelona, Barcelona, Spain) for their valuable contributions to this study. The comments and suggestions of Janneke Verkaik-Kloosterman (RIVM), Birgitte Tiesjema (RIVM), Jacqueline Castenmiller (Netherlands Food and Consumer Product Safety Authority, NVWA) and Anneke Sellis (Dutch Ministry of Health, Welfare and Sport, VWS) on the draft version of the manuscript are acknowledged. Financial support from NVWA and VWS is acknowledged.

\section{References}

1 L. Vargas-Murga, A. Garcia-Alvarez, B. Roman-Vinas, J. Ngo, L. Ribas-Barba, S. J. van den Berg, et al., Plant food supplement (PFS) market structure in EC Member States, methods and techniques for the assessment of individual PFS intake, Food Funct., 2011, 2, 731-739.

2 Regulation (EC) No 178/2002 of the European Parliament and of the Council of 28 January 2002 laying down the general principles and requirements of food law, establishing the European Food Safety Authority and laying down procedures in matters of food safety, Off J Eur Communities, 2002, February 1, vol. L 31, pp. 1-24.

3 Directive 2002/46/EC of the European Parliament and of the Council of 10 June 2002 on the approximation of the laws of the Member States relating to food supplements, Off J Eur Communities, 2002, July 12, vol. L 183, pp. 51-57. 
4 V. Silano, P. Coppens, A. Larranaga-Guetaria, P. Minghetti and R. Roth-Ehrang, Regulations applicable to plant food supplements and related products in the European Union, Food Funct., 2011, 2, 710-719.

5 G. Cousyn, S. Dalfrà, B. Scarpa, J. Geelen, R. Anton, M. Serafini, et al., Project BELFRIT, Eur. Food Feed Law Rev., 2013, 8(3), 187-196.

6 B. Klaus and M. Gherardini, Italy: The Italian Ministry of Health Adopts a Decree that Introduces a New, Common Positive List for the Use of Botanicals in Food Supplements, Eur. Food Feed Law Rev., 2014, 9(3), 196198.

7 Dutch Ministry of Health, Welfare and Sport. Herbal Preparations Decree in the Dutch Commodities Act, Warenwetbesluit Kruidenpreparaten, In Dutch, 2001. Available via: http://wetten.overheid.nl/BWBR0012174/201412-13 (accessed August 5, 2016).

8 European Advisory Services (EAS), 28 March 2007. The use of substances with nutritional or physiological effect other than vitamins and minerals in food supplements. Available via: http://ec.europa.eu/food/safety/docs/labelling_nutrition-sup plements-2007_a540169_study_other_substances_en.pdf.

9 M. J. Martena, J. C. van der Wielen, L. F. van de Laak, E. J. Konings, H. N. de Groot and I. M. Rietjens, Enforcement of the ban on aristolochic acids in Chinese traditional herbal preparations on the Dutch market, Anal. Bioanal. Chem., 2007, 389, 263-275.

10 S. J. van den Berg, L. Serra-Majem, P. Coppens and I. M. Rietjens, Safety assessment of plant food supplements (PFS), Food Funct., 2011, 2, 760-768.

11 C. Di Lorenzo, A. Ceschi, H. Kupferschmidt, S. Lude, E. De Souza Nascimento, A. Dos Santos, et al., Adverse effects of plant food supplements and botanical preparations: a sys- tematic review with critical evaluation of causality, Br. J. Clin. Pharmacol., 2015, 79, 578-592.

12 A. Garcia-Alvarez, B. Egan, S. de Klein, L. Dima, F. M. Maggi, M. Isoniemi, et al., Usage of plant food supplements across six European countries: findings from the PlantLIBRA consumer survey, PLoS One, 2014, 9, e92265.

13 C. T. M. Van Rossum, H. P. Fransen, J. VerkaikKloorsterman, E. J. M. Buurma-Rethans and M. C. Ocké, Dutch National Food Consumption Survey 2007-2010. Diet of children and adults aged 7 to 69 years, RIVM report 350050006/2011, 2011. Available via: http://www.rivm.nl.

14 M. C. Ocké, E. J. M. Buurma-Rethans, E. J. De Boer, C. Wilson-Van den Hooven, Z. Eternad-Ghameshlou and J. J. M. M. Drijvers, et al., Dutch National Food Consumption Survey-Older adults 2010-2012. Diet of community-dwelling older adults, RIVM report 050413001/ 2013. Available via: http://www.rivm.nl.

15 Medicines Evaluation Board - College ter Beoordeling van Geneesmiddelen. Medicines data bank [Geneesmiddeleninformatiebank; in Dutch]. Available from: http://www.cbg-meb.nl/geneesmiddeleninformatiebank (accessed August 5, 2016).

16 A. A. Sprouse and R. B. van Breemen, Pharmacokinetic interactions between drugs and botanical dietary supplements, Drug Metab. Dispos., 2016, 44, 162-171.

17 E. F. Oga, S. Sekine, Y. Shitara and T. Horie, Pharmacokinetic herb-drug interactions: insight into mechanisms and consequencees, Eur. J. Drug Metab. Pharmacokinet., 2016, 41, 93-108.

18 X. W. Chen, K. B. Sneed, S. Y. Pan, C. Cao, J. R. Kanwar, H. Chew, et al., Herb-drug interactions and mechanistic and clinical considerations, Curr. Drug Metab., 2012, 13, 640-651. 